\title{
C5 palsy in the treatment of cervical spondylosis myelopathy with ossification of the posterior longitudinal ligament
}

denglu yan ( $\sim$ yandenglu@163.com )

First People's Hospital of Zhaoqing https://orcid.org/0000-0001-6503-5077

Zaiheng Zhang

Shenzhen Bao an People's hospital

Zhi Zhang

Third Hospital of Guangzhou Medical University

Research article

Keywords: Ossification Ligament Cervical Treatment Fusion

Posted Date: March 9th, 2020

DOI: https://doi.org/10.21203/rs.3.rs-16384/v1

License: (1) This work is licensed under a Creative Commons Attribution 4.0 International License.

Read Full License 


\section{Abstract}

Background There are many factors that affect the C5 palsy in the treatment of cervical spondylosis myelopathy (CSM) with ossification of the posterior longitudinal ligament (OPLL), but the spinal compression degrees may be an important factor in affection on it. Objective The purpose of this study was to evaluate the effect of spinal cord compression degrees on the clinical outcomes of OPLL patients which been treated by anterior and posterior surgery. Methods From May 2010 to October 2017, 145 patients cervical spondylosis myelopathy with OPLL (spinal canal narrowing by the OPLL exceeded 30\%) were enrolled in this study; 76 patients received anterior cervical corpectomy and fusion surgery (ACCF), and 69 patients had posterior cervical decompression and laminoplasty procedures (PCDL). The clinical outcomes of pain relief (visual analog scale, VAS), functional disability (neck disability index, NDI) were recorded at baseline and at the final follow-up. Results There were five patients with C5 palsy in this series cases (two in ACCF and three in PCDL), and the rate is 4.1\% (3.2\% in ACCF and $5.2 \%$ in PCDL, P > 0.05). Five $C 5$ palsy cases had more than $50 \%$ compressed degrees of dural sac and flattened spinal cord, and the compressed dural sac and flattened spinal cord had totally expansion after operation. There were no patients resented with CSF leakage in PCDL group, and six patients presented with CSF leakage in ACCF. The mean postoperative canal diameter were significant better than preoperative in PDL patients $(P<0.01)$. The average spinal sagittal and axial compressive ratio were significantly decreased from preoperative in ACR and PDL groups $(P<0.01)$. The mean cervical ROM values were decreased in ACR and PDL groups $(P<0.05)$. Conclusions Based on the results of this study, anterior and posterior surgery was effective and safe in the treatment of the OPLL patients. The complication of C5 palsy were no related in the surgery methods, but may be related the degrees of spinal cord compressed.

\section{Introduction}

Cervical spondylosis myelopathy (CSM) is a neurological disorder caused by the narrowing of the cervical spinal canal as a result of degenerative changes in the cervical spine with the advancing age in the population.[1-3] Various pathologic processes in the cervical spine may cause mechanical compression of the spinal cord and yield to degenerative cervical myelopathy, and the ossification of the posterior longitudinal ligament (OPLL) has been recognized as one of the most common causes of severe cervical myelopathy.[4,5] Since OPLL is a multifactorial disease and the clinical symptoms are severe and progressive, conservative treatment is not effective and surgical intervention is indicated.[1, 6-8] Surgical strategies for cervical myelopathy due to OPLL can be divided into anterior and posterior approach, and the performed procedures decision was based on the pathologic features of the CSM. $[2,7,8]$ Although anterior and posterior approach has its advantages and limitations, surgery share the same goal of decompression the spinal cord and relieving neurological compression form restore spinal canal space for spinal cord.[6, 9]

Although the surgical strategy for severe OPLL still remains controversial, the surgery of the anterior corpectomy or posterior laminoplasty had good clinical outcomes.[10,11] The posterior laminoplasty recommended for serve OPLL because it is a quick and safe operation resulting in neurological 
improvement from posterior decompression of the cervical spinal cord after laminoplasty.[12, 8] The anterior surgery provide a good surgical outcome for radical decompression by directly removing the OPLL and other anterior pathogenic structures. $[13,14]$ With the development of technology and surgical procedures, the complications of anterior and posterior surgery for OPLL were decreased significantly than before.[15, 8] However, the complication of C5 palsy were not diminished with the development of anterior and posterior surgery. [16-18] The complication of C5 palsy, which been considered main in the posterior surgery, have been found still in the anterior surgery of CSM, especially in OPLL.[19, 13, 1, 9, 20, 21]

The C5 palsy in OPLL patients was the cervical spinal cord injuries, which different from other spinal cord injuries because of ossification induced narrowing of the spinal canal and limitation of intervertebral mobility.[21, 22, 18, 20] There are many factors that affect the C5 palsy in surgical treatment of OPLL, but the spinal canal stenosis and the spinal compression degrees may be an important factor in affection on it. The purpose of this study was to evaluate the effect of spinal canal stenosis and spinal cord compression degrees on the clinical outcomes of OPLL patients which been treated by anterior or posterior surgery in our clinical.

\section{Materials And Methods}

From May 2010 to October 2017, consecutive CMS patients of OPLL (ossification occupying more than $30 \%$ diameter of the spinal canal on computed tomography (CT) and magnetic resonance (MR) images were enrolled in this study. One hundred and forty-five patients initially fulfilled the study criteria, and twenty-four patients were lost to follow-up. Of the remaining 121 patients available for analysis, 63 patients received anterior cervical corpectomy and fusion surgery (ACCF, included 44 men and 19 women with an average age of $51.86 \pm 9.45$ years), and 58 patients had posterior cervical decompression and laminoplasty procedures (PCDL, included 41 men and 17 women with an average age of $52.18 \pm$ 9.62 years). The inclusion criteria were CSM patients of OPLL (ossification occupying more than $30 \%$ diameter of the spinal canal on CT and MR images). Exclusion criteria included pathologic conditions of the cervical spine (trauma, tumor, or infection). The two groups had similar age and sex distribution, ossification occupying, and the pain history (Table 1).

\section{Table 1}

General date of patients (Means \pm SD)

\begin{tabular}{|llllll|}
\hline Group & Gender & & Age & OC & Pain history \\
\hline & Male & Female & (Years) & $(\%)$ & (Months) \\
\hline ACCF (63) & 34 & 29 & $51.86 \pm 9.45$ & $58.54 \pm 9.86$ & $22.43 \pm 6.52$ \\
\hline PCDL (58) & 31 & 27 & $52.18 \pm 9.62$ & $57.69 \pm 8.74$ & $23.75 \pm 7.38$ \\
\hline \multicolumn{4}{l}{ Note: OC = Ossification occupying. There was no significant difference between two groups } \\
\hline
\end{tabular}




\section{Surgical Procedures}

Under general anesthesia, the ACCF procedure was performed in the standard fashion reported in previous studies. $[6,2,23]$ The OPLL was separated from dura and meticulously separated using the micro dissector and removed by Kerrison rongeur or micro curettes. If the OPLL was associated with dural ossification, this portion of dura was carefully preserved using the anterior floating method to avoid dural tears (Fig. 1). The PCDL procedure was performed in the standard fashion reported in previous studies, and ligamentum flava at the cranial and caudal ends of the intended laminar expansion was removed by a thin-bladed rongeur (Fig. 1).[16, 17, 24] Brace support was recommended for 4-6 weeks after surgery.

\section{Critical Of Clinical Outcomes}

The clinical outcomes of pain relief (visual analog scale, VAS), functional disability (neck disability index, NDI) were recorded at baseline and at the final follow-up. All patients had preoperative and post-operative plain radiographs, CT scans, and magnetic resonance (MR) images. The focus was to evaluate five radiographic characteristics at follow-up: (1) cervical lordosis, (2) Sagittal spinal canal diameter, (3) the ossification of the most stenotic area, (4) status of spinal cord (spinal cord compression or decompression).

\section{Statistical analysis}

All measurements were performed by a single observer and are expressed as means \pm SD. Using the SPSS 17.0 statistics software, classic t-test and chi-square test were performed.

\section{Results}

There was no intraoperative death in this series. In ends 121 cases had follow-up at least one year and 24 cases lost, and the follow-up rate was $82.89 \%$ (63/76) in ACCF group and 84.06\% (58/69) in PCDL group $(P>0.05)$. The followed time was from 18 to 31 months (average 23 months), and average $23.57 \pm$ 6.42 months in ACCF group and $24.38 \pm 7.73$ months in PCDL group $(P>0.05)$.

There were five patients with $\mathrm{C} 5$ palsy in this series cases (two in ACCF and three in PCDL), and the rate is $4.1 \%$ (3.2\% in ACCF and 5.2\% in PCDL, $\mathrm{P}>0.05$ ). Five C5 palsy cases were the most compressed degrees of dural sac and flattened spinal cord more than $50 \%$, and all had totally expansion after operation. The two patients with C5 palsy were recovered after 3 months of neurotrophy drugs, hyperbaric oxygen and rehabilitation training after the operation. Three complications of bilateral C5 palsy related to PCDL group patients. C5 palsy developed at immediately postoperatively, and the patient was treated conservatively including neurotrophy drugs, high-pressure oxygen therapy, and functional exercises. Two case strength of the paralyzed muscles recovered one case after three months, the other case did not recover which can capable of independent self-care after three courses of hyperbaric oxygen and rehabilitation training 1 year after the operation. 
There were no patients resented with cerebrospinal fluid (CSF) leakage in PCDL group. Six patients presented with CSF leakage in ACCF, which indicated dural defect and tearing during the operation. When CSF leakage occurred after operation, the drainage tube was pulled out 24 hours after operation and continuous pressure to the wound was applied. CSF leakage disappeared in six cases after operation seven days. All patients achieved spinal fusion with no cases of cage extrusion. Implant failure and instability were not seen on lateral flexion/extension radiographs of the cervical spine.

The average operational time, blood loose, and hospital days were showed in Table 2. The average operation time, blood loose and hospital days was $114.56 \pm 26.85$ minutes, $167.65 \pm 36.38 \mathrm{~mL}$ and $8.62 \pm$ 2.45 days in ACCF group; $112.37 \pm 28.29$ minutes, $162.77 \pm 37.65 \mathrm{~mL}$ and $8.76 \pm 2.36$ days in PCDL groups; $95.73 \pm 27.54$ minutes. There was no significant difference between two groups in operation time, blood loose and hospital days $(P>0.05)$.

Table 2

Follow up time and operation date of patients (Means \pm SD)

\begin{tabular}{|c|c|c|c|c|c|}
\hline \multirow[t]{2}{*}{ Group } & \multicolumn{2}{|l|}{ Follow up* } & \multirow{2}{*}{$\begin{array}{l}\text { Operation time* } \\
\text { (Minutes) }\end{array}$} & \multirow{2}{*}{$\begin{array}{l}\text { Blood loss* } \\
(\mathrm{mL})\end{array}$} & \multirow{2}{*}{$\begin{array}{l}\text { Hospital days* } \\
\text { (Days) }\end{array}$} \\
\hline & Rate & Time (Month) & & & \\
\hline ACCF & $82.89 \%(63 / 76)$ & $23.57 \pm 6.42$ & $114.56 \pm 26.85$ & $167.65 \pm 36.38$ & $8.62 \pm 2.45$ \\
\hline PCDL & $84.06 \%(58 / 69)$ & $24.38 \pm 7.73$ & $112.37 \pm 28.29$ & $162.77 \pm 37.65$ & $8.76 \pm 2.36$ \\
\hline \multicolumn{6}{|c|}{$\begin{array}{l}\text { There was no significant difference among three groups on follow up, operation time, blood loss, and } \\
\text { hospital days }(P>0.05)\end{array}$} \\
\hline \multicolumn{6}{|c|}{$\begin{array}{l}\text { The average VAS, NDI, cervical lordosis and canal diameter were showed in Table } 3 \text {. The mean } \\
\text { postoperative VAS was significantly better than preoperative (from } 8.67 \pm 1.49 \text { to } 1.15 \pm 0.37 \text { in ACCF, } \\
\text { and from } 8.61 \pm 1.53 \text { to } 1.56 \pm 0.48 \text { in } P C D L, P<0.01) \text {, and no significant difference between two } \\
\text { groups }(P>0.05) \text {. The average postoperative NDL were significantly better than preoperative (from } \\
66.83 \pm 15.26 \text { to } 11.17 \pm 3.39 \text { in ACCF, and from } 65.92 \pm 14.78 \text { to } 13.64 \pm 5.53 \text { in } P C D L, P<0.01) \text {, and } \\
\text { no significant difference between two groups }(P>0.05) \text {. The VAS and NDI were improved all patients } \\
\text { in ACCF patients, and no change in two patients in PCDL. }\end{array}$} \\
\hline \multicolumn{6}{|c|}{$\begin{array}{l}\text { The mean postoperative canal diameter was no significant difference compare to preoperative in } \\
\text { ACCF patients (from } 12.46 \pm 1.76 \text { to } 12.37 \pm 1.82 \mathrm{~mm}, \mathrm{P}>0.05) \text {, and had significantly better than } \\
\text { preoperative in PCDL patients (from } 12.65 \pm 1.63 \text { to } 18.34 \pm 2.67 \mathrm{~mm}, \mathrm{P}<0.01) \text {. The spinal average } \\
\text { sagittal and axial compressive ratio were significantly decreased from preoperative } 62.58 \pm 14.61 \text { to } \\
2.12 \pm 1.26 \text { and } 63.65 \pm 15.83 \text { to } 2.61 \pm 1.53 \text { in } A C C R \text { group }(P<0.01) \text {, and from preoperative } 63.89 \pm \\
15.46 \text { to } 3.48 \pm 1.39 \text { and } 64.76 \pm 16.35 \text { to } 3.55 \pm 1.54 \text { in } P C D L \text { group }(P<0.01) \text {. }\end{array}$} \\
\hline
\end{tabular}


Table 3

Clinical results date of patients (Means \pm SD)

\begin{tabular}{|c|c|c|c|c|}
\hline \multirow{2}{*}{ Group } & \multicolumn{2}{|l|}{ ACCF } & \multicolumn{2}{|l|}{ PCDL } \\
\hline & Preoperative & Postoperative & Preoperative & Postoperative \\
\hline VAS & $8.67 \pm 1.49$ & $1.15 \pm 0.37$ & $8.61 \pm 1.53$ & $1.56 \pm 0.48$ \\
\hline ODI & $66.83 \pm 15.26$ & $11.17 \pm 3.39$ & $65.92 \pm 14.78$ & $13.64 \pm 5.53$ \\
\hline $\mathrm{CD}(\mathrm{mm})$ & $12.46 \pm 1.76$ & $12.37 \pm 1.82$ & $12.65 \pm 1.63$ & $18.34 \pm 2.67$ \\
\hline SSCR (\%) & $62.58 \pm 14.61$ & $2.12 \pm 1.26$ & $63.89 \pm 15.46$ & $3.48 \pm 1.39$ \\
\hline SACR (\%) & $63.65 \pm 15.83$ & $2.61 \pm 1.53$ & $64.76 \pm 16.35$ & $3.55 \pm 1.54$ \\
\hline CL (deg) & $9.68 \pm 2.37$ & $8.57 \pm 2.52$ & $9.57 \pm 2.63$ & $8.49 \pm 2.48$ \\
\hline ROM (deg) & $23.15 \pm 8.34$ & $16.35 \pm 5.72$ & $23.41 \pm 7.69$ & $16.47 \pm 5.46$ \\
\hline \multicolumn{5}{|c|}{$\begin{array}{l}\mathrm{CL}=\text { Cervical lordosis, } \mathrm{CD}=\text { Canal diameter, } \mathrm{SCR}=\text { Spinal sagittal compressive ratio, } \mathrm{SACR}=\text { Spinal } \\
\text { axial compressive ratio }\end{array}$} \\
\hline \multicolumn{5}{|c|}{$\begin{array}{l}\text { The average cervical lordosis was no difference compare to preoperative (from } 9.68 \pm 2.37 \text { to } 8.57 \pm \\
2.52 \text { degrees in } A C C F \text {, and from } 9.57 \pm 2.63 \text { to } 8.49 \pm 2.48 \text { degrees in } P C D L, P>0.05) \text {, and no } \\
\text { significant difference between two groups }(P>0.05) \text {. The mean cervical ROM values were decreased } \\
\text { from } 23.15 \pm 8.34 \text { degrees preoperative to } 16.35 \pm 5.72 \text { degrees postoperatively in ACCF patients }(P< \\
0.05) \text {, and from } 23.41 \pm 7.69 \text { degrees preoperative to } 16.47 \pm 5.46 \text { degrees postoperatively in } P C D L \\
\text { patients }(P<0.05) \text {. }\end{array}$} \\
\hline
\end{tabular}

\section{Discussion}

Ossification of the posterior longitudinal ligament is a common cervical disease that can cause stenotic changes in the spinal canal and contribute to the development of quadriparesis $[9,25,8]$. Conservative treatment may be effective for some patients. However, for most of the patients, surgical decompression of the spinal cord to prevent the progression of neurological deterioration as rapidly as possible is the most effective measure $[25,26]$. In general, anterior decompressions by cervical corpectomy and resection of OPLL seem to be an ideal surgical option, and posterior decompression is an alternative choice for severe OPLL when the anterior approach threatens iatrogenic deterioration of the neurological status $[9,27,26,8,23]$. The results of this study demonstrated the anterior corpectomy and some advantages on the complication of C5 palsy than posterior laminoplasty for OPLL. Although C5 palsy were two in ACCF and three in PCDL, the recovered cases were better in ACCF than PCDL.

It is commonly believed that the spinal cord drift and subsequent stretching of the $\mathrm{C} 5$ nerve root, which is more vulnerable than the other roots because of the $\mathrm{C} 5$ level, are typically at the apex of the cervical lordosis $[27,17,20]$. Because OPLL affects chiefly the cervical spine form C3 to C5, the extent of posterior shifting of the cord is greatest at the $C 5$ level $[28,26,21]$. The cervical spinal cord is compressed and flattened by OPLL, and reduction of the blood supply in the grey matter in the ventral portion of the dorsal 
columns for small bold vessels was compressed. There may be compression of the spina roots when ossification extends to one of the lateral recesses of the spinal canal $[25,26,21]$. The degrees of spinal cord drift were more in PCDL than in ACCF, and five complication of $\mathrm{C} 5$ palsy were two in ACCF and three in PCDL in this series cases. For this reason, the spinal cord drift may not the reason for complication of C5 palsy in surgery.

Spinal cord movement is limited because the organ is tethered to nerve roots after common laminectomy $[25,17,21]$. The complication of C5 palsy were not only in anterior corpectomy, but also in posterior laminoplasty. Previous study shown the complication of C5 palsy is associated with the extent of decompression $[29,24,20]$. CSM can result in regional cord ischemia from the sural sac an spinal cord flattened by OPLL, and long term ischemia leads to an imbalance between spinal cord metabolic demand and oxygen supply [30, 26, 31, 32]. After surgery of ACCF and PCDL, the dural sac and flattened spinal cord were all expansion in this series cases. As previous study shown, the dural sac and spinal cord expansion can lead to spinal cord ischemia-reperfusion injury [33, 20, 31, 34]. In this series, the compression of spinal and expansion of dural sac and flattened spinal cord were similar between two groups. The five C5 palsy cases were the most compressed degrees of dural sac and flattened spinal cord more than $50 \%$, and all had totally expansion after operation. For this reason, the complication may be related to the compression and expansion of spinal cord.

Long term of OPLL compression spinal cord in CSM patients lead the nerve tissue is starved of vital nutrients such as oxygen and glucose [35, 33, 26, 34]. Multiple mechanisms of cell damage are activated following spinal ischemia and reperfusion which can be a function of location in the spine as well as the time elapsed since the onset of ischemia [30, 3, 27, 36, 32]. Inflammatory responses are known as a major component of secondary injury of initial ischemic insult and play an important role in modulating the pathogenesis of C5 palsy [37, 8, 24, 20]. Effects of reperfusion, also known as reperfusion injury, are the causative factors for spinal edema $[38,25,8,18]$. The results of this study shown the complication of C5 palsy in PCDL were serve than ACCF may be related the spinal ischemia and reperfusion injury. The spinal cord drift in ACCF patients were less than PCDL patients, this maybe causes the more serious of spinal ischemia and reperfusion injury. Despite of ACCF and PCDL can get good clinical results in OPLL patients, the tenets of $\mathrm{C} 5$ palsy prevention by evaluated the risk factors are important in clinical practice.

\section{Conclusion}

Based on the results of this study, anterior and posterior surgery was effective and safe in the treatment of the OPLL patients. The complication of $\mathrm{C} 5$ palsy were no related in the surgery methods, but may be related the degrees of spinal cord compressed.

\section{Abbreviations}

CSM: cervical spondylosis myelopathy 
OPLL: ossification of the posterior longitudinal ligament

ACCF: anterior cervical corpectomy and fusion

PCDL: posterior cervical decompression and laminoplasty

CT: computed tomography

MR: magnetic resonance

VAS: visual analog scale

NDI: neck disability index

\section{Declarations}

\section{Ethical approval and consent to participate}

This study was approved by the hospital ethics committee of the First People's Hospital of Zhaoqing, Zhaoqing City, Guangdong Province, and all patients signed had informed consent.

\section{Consent for publication}

Author Denglu Yan, Zaiheng Zhang, and Zhi Zhang all agree to publication.

\section{Availability of data and materials}

The datasets are available under reasonable request.

\section{Funding}

Not applicable of funding on this work.

\section{Conflict of Interest}

Author Denglu Yan, Zaiheng Zhang, and Zhi Zhang declare that they have no conflict of interest.

\section{Authors' contributions}

DY participated in the design of the study and drafted the manuscript. ZZh participated in the design of the study and coordination and helped to draft the manuscript. ZZ participated in the design of the study and performed the statistical analysis. All authors read and approved the final manuscript.

\section{Acknowledgements}

We sincerely appreciated the genial help from all scholars who contributed to our research. 


\section{Author details}

${ }^{1}$ First People's Hospital of Zhaoqing, Zhaoqing, 526000, China

2 People's Hospital of Baoan, Shenzhen, 518101, China

${ }^{3}$ Third Hospital of Guangzhou Medical University, Guangzhou, 510150, China

\section{References}

1. Sun J, Shi J, Xu X, Yang Y, Wang Y, Kong Q, Yang H, Guo Y, Han D, Jiang J, Shi G, Yuan W, Jia L (2018) Anterior controllable antidisplacement and fusion surgery for the treatment of multilevel severe ossification of the posterior longitudinal ligament with myelopathy: preliminary clinical results of a novel technique. Eur Spine J 27 (6):1469-1478. doi:10.1007/s00586-017-5437-4

2. Mizuno J, Nakagawa H (2002) Anterior decompression for cervical spondylosis associated with an early form of cervical ossification of the posterior longitudinal ligament. Neurosurg Focus 12 (1):E12

3. Masaki Y, Yamazaki M, Okawa A, Aramomi M, Hashimoto M, Koda M, Mochizuki M, Moriya H (2007) An analysis of factors causing poor surgical outcome in patients with cervical myelopathy due to ossification of the posterior longitudinal ligament: anterior decompression with spinal fusion versus laminoplasty. J Spinal Disord Tech 20 (1):7-13. doi:10.1097/01.bsd.0000211260.28497.35

4. Miyazaki M, Ishihara T, Notani N, Kanezaki S, Abe T, Tsumura H (2018) Relationship of preoperative intramedullary MRI signal intensity and dynamic factors with surgical outcomes of laminoplasty for cervical ossification of the posterior longitudinal ligament. Clin Neurol Neurosurg 174:117-122. doi:10.1016/j.clineuro.2018.09.018

5. Yuan W, Zhu Y, Liu X, Zhu H, Zhou X, Zhou R, Cui C, Li J (2015) Postoperative three-dimensional cervical range of motion and neurological outcomes in patients with cervical ossification of the posterior longitudinal ligament: Cervical laminoplasty versus laminectomy with fusion. Clin Neurol Neurosurg 134:17-23. doi:10.1016/j.clineuro.2015.04.004

6. Chen Y, Chen D, Wang X, Lu X, Guo Y, He Z, Tian H (2009) Anterior corpectomy and fusion for severe ossification of posterior longitudinal ligament in the cervical spine. Int Orthop 33 (2):477-482. doi:10.1007/s00264-008-0542-y

7. Meyer SA, Wu JC, Mummaneni PV (2011) Laminoplasty outcomes: is there a difference between patients with degenerative stenosis and those with ossification of the posterior longitudinal ligament? Neurosurg Focus 30 (3):E9. doi:10.3171/2011.1.FOCUS10279

8. Matsumoto M, Chiba K, Toyama Y (2012) Surgical treatment of ossification of the posterior longitudinal ligament and its outcomes: posterior surgery by laminoplasty. Spine (Phila Pa 1976) 37 (5):E303-308. doi:10.1097/BRS.0b013e318239cca0

9. Iwasaki M, Okuda S, Miyauchi A, Sakaura H, Mukai Y, Yonenobu K, Yoshikawa H (2007) Surgical strategy for cervical myelopathy due to ossification of the posterior longitudinal ligament: Part 2: 
Advantages of anterior decompression and fusion over laminoplasty. Spine (Phila Pa 1976) 32

(6):654-660. doi:10.1097/01.brs.0000257566.91177.cb

10. Fujiwara H, Oda T, Makino T, Moriguchi Y, Yonenobu K, Kaito T (2018) Impact of Cervical Sagittal Alignment on Axial Neck Pain and Health-related Quality of Life After Cervical Laminoplasty in Patients With Cervical Spondylotic Myelopathy or Ossification of the Posterior Longitudinal Ligament: A Prospective Comparative Study. Clin Spine Surg 31 (4):E245-E251. doi:10.1097/BSD.0000000000000619

11. Kang MS, Kim KH, Park JY, Kuh SU, Chin DK, Kim KS, Jin BH, Cho YE (2019) Progression of Cervical Ossification of Posterior Longitudinal Ligament After Laminoplasty or Laminectomy With Posterior Fixation. Clin Spine Surg. doi:10.1097/BSD.0000000000000898

12. Kawaguchi Y, Nakano M, Yasuda T, Seki S, Suzuki K, Yahara Y, Makino H, Kobayashi K, Kanamori M, Kimura T (2019) Clinical Impact of Ossification of the Posterior Longitudinal Ligament Progression After Cervical Laminoplasty. Clin Spine Surg 32 (3):E133-E139. doi:10.1097/BSD.0000000000000747

13. Qin R, Chen X, Zhou P, Li M, Hao J, Zhang F (2018) Anterior cervical corpectomy and fusion versus posterior laminoplasty for the treatment of oppressive myelopathy owing to cervical ossification of posterior longitudinal ligament: a meta-analysis. Eur Spine J 27 (6):1375-1387. doi:10.1007/s00586017-5451-6

14. Yoo S, Ryu D, Choi HJ, Kuh SU, Chin DK, Kim KS, Cho YE (2017) Ossification foci act as stabilizers in continuous-type ossification of the posterior longitudinal ligament: a comparative study between laminectomy and laminoplasty. Acta Neurochir (Wien) 159 (9):1783-1790. doi:10.1007/s00701-0173233-x

15. Kimura A, Shiraishi Y, Sugawara R, Inoue H, Endo T, Takeshita K (2019) Impact of K-Line (-) in the Neck-Flexion Position on Patient-reported Outcomes After Cervical Laminoplasty For Patients With Ossification of the Posterior Longitudinal Ligament. Clin Spine Surg. doi:10.1097/BSD.0000000000000891

16. Katsumi K, Izumi T, Ito T, Hirano T, Watanabe K, Ohashi M (2016) Posterior instrumented fusion suppresses the progression of ossification of the posterior longitudinal ligament: a comparison of laminoplasty with and without instrumented fusion by three-dimensional analysis. Eur Spine $\mathrm{J} 25$ (5):1634-1640. doi:10.1007/s00586-015-4328-9

17. Ahsan MK, Awwal MA, Khan SI, Zaman N, Haque MH, Zahangiri Z (2017) Open-door Laminoplasty for Multilevel Cervical Spondylotic Myelopathy and Ossification of the Posterior Longitudinal Ligament (OPLL) using Titanium Reconstruction Miniplate and Screws. Mymensingh Med J 26 (3):558-568

18. Oshina M, Segawa T, Oshima $Y$, Tanaka S, Inanami H (2020) C5 palsy after C5/6/7 posterior foraminal decompression: A case report. Medicine (Baltimore) 99 (3):e18817. doi:10.1097/MD.0000000000018817 
19. Koda M, Mochizuki M, Konishi H, Aiba A, Kadota R, Inada T, Kamiya K, Ota M, Maki S, Takahashi K, Yamazaki M, Mannoji C, Furuya T (2016) Comparison of clinical outcomes between laminoplasty, posterior decompression with instrumented fusion, and anterior decompression with fusion for K-line (-) cervical ossification of the posterior longitudinal ligament. Eur Spine J 25 (7):2294-2301. doi:10.1007/s00586-016-4555-8

20. Pennington Z, Lubelski D, Westbroek EM, Cottrill E, Ehresman J, Goodwin ML, Lo SF, Witham TF, Theodore N, Bydon A, Sciubba DM (2020) Spinal cord float back is not an independent predictor of postoperative C5 palsy in patients undergoing posterior cervical decompression. Spine J 20 (2):266275. doi:10.1016/j.spinee.2019.09.017

21. Usami Y, Nakaya Y, Hayama S, Nakano A, Fujishiro T, Neo M (2020) Impact of Multifidus Muscle Swelling on C5 Palsy After Cervical Laminoplasty. Spine (Phila Pa 1976) 45 (1):E10-E17. doi:10.1097/BRS.0000000000003205

22. Woodroffe RW, Helland LC, Bryant A, Nourski KV, Yamaguchi S, Close L, Noeller J, Teferi N, Maley JE, Hitchon PW (2020) Intraoperative Shoulder Traction as Cause of C5 Palsy: Magnetic Resonance Imaging Study. World Neurosurg. doi:10.1016/j.wneu.2020.01.024

23. Isu T, Minoshima S, Mabuchi S (1997) Anterior decompression and fusion using bone grafts obtained from cervical vertebral bodies for ossification of the posterior longitudinal ligament of the cervical spine: technical note. Neurosurgery 40 (4):866-869; discussion 869-870. doi:10.1097/00006123-199704000-00046

24. Seichi A, Hoshino Y, Kimura A, Nakahara S, Watanabe M, Kato T, Ono A, Kotani Y, Mitsukawa M, ljiri K, Kawahara N, Inami S, Chikuda H, Takeshita K, Nakagawa Y, Taguchi T, Yamazaki M, Endo K, Sakaura H, Uchida K, Kawaguchi Y, Neo M, Takahashi M, Harimaya K, Hosoe H, Imagama S, Taniguchi S, Ito T, Kaito T, Chiba K, Matsumoto M, Toyama Y (2011) Neurological complications of cervical laminoplasty for patients with ossification of the posterior longitudinal ligament-a multi-institutional retrospective study. Spine (Phila Pa 1976) 36 (15):E998-1003. doi:10.1097/BRS.0b013e3181fda7fa

25. Sakai K, Okawa A, Takahashi M, Arai Y, Kawabata S, Enomoto M, Kato T, Hirai T, Shinomiya K (2012) Five-year follow-up evaluation of surgical treatment for cervical myelopathy caused by ossification of the posterior longitudinal ligament: a prospective comparative study of anterior decompression and fusion with floating method versus laminoplasty. Spine (Phila Pa 1976) 37 (5):367-376. doi:10.1097/BRS.0b013e31821f4a51

26. Nakajima H, Watanabe S, Honjoh K, Kitade I, Sugita D, Matsumine A (2019) Long-Term Outcome of Anterior Cervical Decompression with Fusion for Cervical Ossification of Posterior Longitudinal Ligament including Postsurgical Remnant Ossified Spinal Lesion. Spine (Phila Pa 1976). doi:10.1097/BRS.0000000000003173

27. Yang H, Sun J, Shi J, Shi G, Guo Y, Yang Y (2018) Anterior Controllable Antedisplacement Fusion (ACAF) for Severe Cervical Ossification of the Posterior Longitudinal Ligament: Comparison with Anterior Cervical Corpectomy with Fusion (ACCF). World Neurosurg 115:e428-e436. doi:10.1016/j.wneu.2018.04.065 
28. Liu X, Li T, Shi L, Luo Y, Chen D, Xu B, Chen Y (2019) Extended Laminoplasty for Ossification of Posterior Longitudinal Ligament Involving the C2 Segment. World Neurosurg 130:317-323. doi:10.1016/j.wneu.2019.07.086

29. Takeuchi K, Yokoyama T, Wada KI, Kudo H (2019) Relationship between Enlargement of the CrossSectional Area of the Dural Sac and Neurological Improvements after Cervical Laminoplasty: Differences between Cervical Spondylotic Myelopathy and Ossification of the Posterior Longitudinal Ligament. Spine Surg Relat Res 3 (1):27-36. doi:10.22603/ssrr.2018-0008

30. Lee DH, Cho JH, Lee CS, Hwang CJ, Choi SH, Hong CG (2018) A novel anterior decompression technique (vertebral body sliding osteotomy) for ossification of posterior longitudinal ligament of the cervical spine. Spine J 18 (6):1099-1105. doi:10.1016/j.spinee.2018.02.022

31. Caton MT, Huff JS (2020) Spinal Cord Ischemia. In: StatPearls. Treasure Island (FL),

32. Pasqualucci A, Al-Sibaie A, Vaidyan KPT, Paladini A, Nadhari MY, Gori F, Greiss HF, Properzi M, Al Ani OSM, Godwin A, Syedkazmi AH, Elhanf OA, Varrassi G (2020) Epidural Corticosteroids, Lumbar Spinal Drainage, and Selective Hemodynamic Control for the Prevention of Spinal Cord Ischemia in Thoracoabdominal Endovascular Aortic Repair: A New Clinical Protocol. Adv Ther 37 (1):272-287. doi:10.1007/s12325-019-01146-7

33. Kim B, Yoon DH, Shin HC, Kim KN, Yi S, Shin DA, Ha Y (2015) Surgical outcome and prognostic factors of anterior decompression and fusion for cervical compressive myelopathy due to ossification of the posterior longitudinal ligament. Spine J 15 (5):875-884.

doi:10.1016/j.spinee.2015.01.028

34. Klinkova A, Kamenskaya O, Ashurkov A, Murtazin V, Orlov K, Lomivorotov VV, Karaskov A (2020) The Clinical Outcomes in Patients with Critical Limb Ischemia One Year after Spinal Cord Stimulation. Ann Vasc Surg 62:356-364. doi:10.1016/j.avsg.2018.12.093

35. Yoshii T, Sakai K, Hirai T, Yamada T, Inose H, Kato T, Enomoto M, Tomizawa S, Kawabata S, Arai Y, Okawa A (2016) Anterior decompression with fusion versus posterior decompression with fusion for massive cervical ossification of the posterior longitudinal ligament with $a>/=50 \%$ canal occupying ratio: a multicenter retrospective study. Spine J 16 (11):1351-1357. doi:10.1016/j.spinee.2016.07.532

36. Lei T, Shen Y, Wang LF, Cao JM, Ding WY, Ma QH (2012) Cerebrospinal fluid leakage during anterior approach cervical spine surgery for severe ossification of the posterior longitudinal ligament: prevention and treatment. Orthop Surg 4 (4):247-252. doi:10.1111/os.12007

37. Morishita S, Yoshii T, Okawa A, Fushimi K, Fujiwara T (2019) Perioperative complications of anterior decompression with fusion versus laminoplasty for the treatment of cervical ossification of the posterior longitudinal ligament: propensity score matching analysis using a nation-wide inpatient database. Spine J 19 (4):610-616. doi:10.1016/j.spinee.2018.10.013

38. Matsuoka Y, Endo K, Nishimura H, Suzuki H, Sawaji Y, Takamatsu T, Seki T, Murata K, Konishi T, Yamamoto K (2018) Cervical Kyphotic Deformity after Laminoplasty in Patients with Cervical Ossification of Posterior Longitudinal Ligament with Normal Sagittal Spinal Alignment. Spine Surg Relat Res 2 (3):210-214. doi:10.22603/ssrr.2017-0078 


\section{Figures}

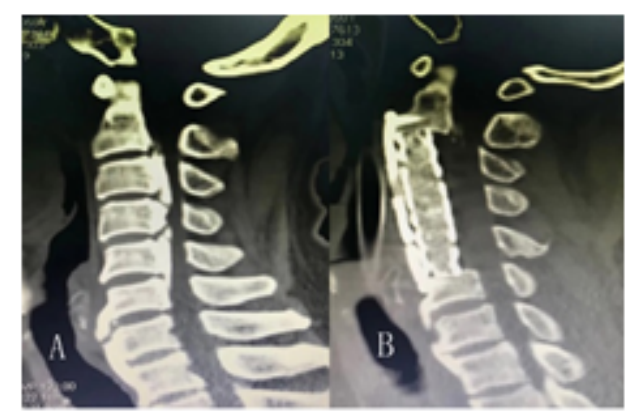

\section{Figure 1}

Male patient with 50 years old had serve OPLL take ACCF procedures, preoperative (A) and postoperative (B) images of CT scan. This patient with C5 palsy were recovered after three months of neurotrophy drugs, hyperbaric oxygen and rehabilitation training after the operation. This patient had cerebrospinal fluid leakage, the drainage tube was pulled out 24 hours after operation and continuous pressure to the wound was applied and CSF leakage disappeared in seven days

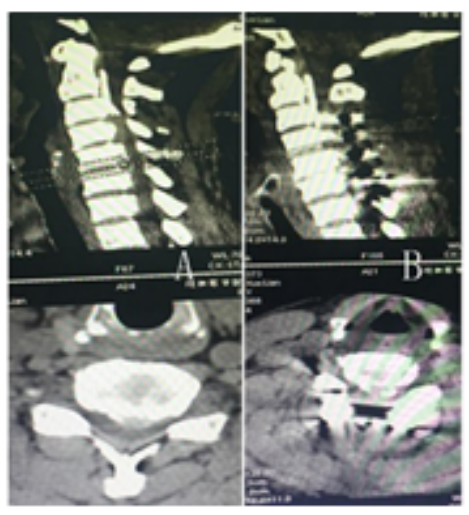

\section{Figure 2}

Female patient with 46 years old had serve OPLL take PCDL procedures, preoperative $(A)$ and postoperative (B) images of CT scan. This patient with bilateral C5 palsy at immediately postoperatively, and did not recovered which can capable of independent self-care after three courses of hyperbaric oxygen and rehabilitation training 1 year after the operation 